\title{
A Comparative Survey of Leguminous Plants as Sources of the Isoflavones, Genistein and Daidzein: Implications for Human Nutrition and Health
}

\author{
PETER B. KAUFMAN, ${ }^{1}$ JAMES A. DUKE, ${ }^{2}$ HARRY BRIELMANN, ${ }^{1}$ JOHN BOIK, ${ }^{3}$ \\ and JAMES E. HOYT ${ }^{1}$
}

\begin{abstract}
Over 80 taxa of mostly agriculturally important legumes were surveyed as sources of the metabolites, genistein and daidzein. Remarkably high concentrations (over $2 \mathbf{g} \cdot \mathbf{k g}^{-1} \mathrm{dry}$ weight) of the anticancer metabolite, genistein, were found in the leaves of Psoralea corylifolia (Indian bread root). All other legumes, with the exception of fermented soybean miso, had genistein levels $<400 \mathrm{mg} \cdot \mathrm{kg}^{-1}$ dry weight. Concentrations of over $1 \mathrm{~g} \cdot \mathrm{kg}^{-1} \mathrm{dry}$ weight and $0.95 \mathrm{~g} \cdot \mathrm{kg}^{-1}$ dry weight of the anticancer metabolite, daidzein, were found in the stems of the fava bean (Vicia faba) and roots of kudzu vine (Pueraria lobata), respectively. From this survey, our results indicate that the legumes, lupine (Lupinus spp.), fava bean, (Vicia faba), soybeans (Glycine max), kudzu (Pueraria lobata), and psoralea (Psoralea corylifolia), are excellent food sources for both genistein and daidzein. Miso, a fermented soybean product, is also a rich source of both isoflavones.
\end{abstract}

\section{INTRODUCTION}

$\mathbf{M}$ any legumes (members of the bean family, Fabaceae) are important sources of the isoflavone secondary metabolites, genistein (1) and daidzein (2), in addition to their being excellent sources of dietary protein. In one of these legumes, namely seedlings of soybeans (Glycine max), the isoflavones, including genis-

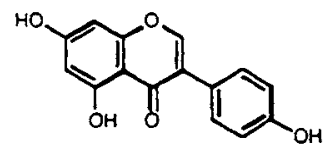

(1)

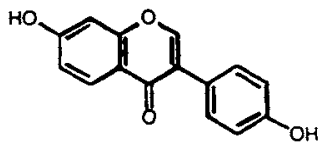

(2) tein and daidzein, are the predominant metabolites present (Graham, 1995). They, or derivatives from them, are known to play a role in deterring attack of host plants by pathogenic fungi (Dixon et al., 1983; Graham, 1995; Lindsay et al., 1993; Oomen et al., 1994). Furthermore, daidzein, and perhaps genistein, act as signaling molecules in the establishment of symbiotic nitrogen-fixing bacteria in roots of leguminous plants such as soybeans (Zhang and Smith, 1995).

Our interest in these compounds derives from the fact that genistein and daidzein are important medicinal compounds (reviewed by

\footnotetext{
${ }^{1}$ Department of Biology, University of Michigan, 4103B Natural Science Building, 830 North University Street, Ann Arbor, MI 48109-1048, USA.

${ }^{2}$ USDA/ARS/NGRL, Beltsville, MD 20705-2350.

${ }^{3}$ Oregon Medical Press, Princeton, MN 55371.
} 
Boik, 1996, and Duke, 1995). Genistein is a promising anticancer agent that inhibits platelet aggregation, induces apoptosis, inhibits leukotriene production, inhibits DNA topoisomerase II, inhibits angiogenesis, reduces the bioavailability of sex hormones, and induces differentiation in cancer cells (reviewed by Boik, 1996; Fotsis et al., 1995; Kennedy, 1995; Matsukawa et al., 1993; and Peterson, 1995). Its ability to act in these ways may be related to its action involving the inhibition of protein tyrosine kinases (Uckun et al., 1995). It is of interest, in this connection, that the epidemiological evidence has linked high soybean, adzuki bean, and mung bean diets in Asian populations with reduced cancer risks (Duke, 1987; Kennedy, 1995). Daidzein acts as an anticancer agent by inducing differentiation in B16 melanoma and HL-60 human leukemia cells (Boik, 1996). Its glucoside, daidzin, obtained from the kudzu vine (Pueraria lobata), has been shown to inhibit the enzyme ALDHI, an NAD-dependent aldehyde dehydrogenase that catalyzes the oxidation of acetaldehyde, the primary product of alcohol metabolism (Duke, 1995). As such, it has been investigated as a treatment for alcoholism.

It should be mentioned here that both genistein and daidzein have phytoestrogen activity. In the human intestine, soy foods produce equol, an estrogen-like compound with an activity of approximately $0.2 \%$ of estradiol (Boik, 1996). Although this is a low activity level, the amount produced from soy food products can result in levels of equol that result in significant competition for estrogen receptors. Because of the estrogenic activity of these two isoflavones, this effect could be quite serious if they were taken by women of child bearing age. Further, there is also a lot of concern about the long-term effects of cumulative small doses of such compounds on male fertility. Finally, a word of caution needs to be mentioned about the phytotoxicity of psoralens in some plants, for example, Psoralea species. Photoactivated psoralens have been used to treat psoriasis since the 1950s. This therapy can be carcinogenic and is only performed in carefully qualified and monitored regimes. High levels of photoactivated psoralens can also cause immunosuppression (Boik, 1995).
The primary objective of the present study was to survey a wide variety of legumes, most of which are agriculturally important crop plants, in order to identify those with the highest concentrations of genistein and daidzein. Such plants, used as food sources by humans, may potentially also serve as excellent sources of these medicinally important isoflavones. To date, the lack of data on optimal plants sources, as pointed out by Stafford (1990), has hindered the development of genistein and daidzeincontaining formulations for use in cancer prevention, cancer treatment, and for treatment of individuals who are alcoholics. In this paper, we present new findings on which of the nutritionally important legumes and legume food products surveyed are the best sources of these isoflavones.

\section{MATERIALS AND METHODS}

Legume seeds were obtained from commercial sources by Dr. James A. Duke, National Germplasm Resources Laboratory, United States Department of Agriculture, Beltsville, Maryland. Seeds were stored at $4^{\circ} \mathrm{C}$ until use for genistein and daidzein analysis or for germination. Voucher specimens of plants were made for every accession used for the analysis of genistein and daidzein in vegetative plant parts and are on deposit in our laboratory in the Department of Biology at the University of Michigan. Voucher seed specimens were also kept for every accession tested.

\section{Plant growth}

Seeds of legumes germinated in the greenhouse were planted at a depth of twice the diameter of the seeds. Plants were grown under fluorescent lamps operating $24 \mathrm{hr}$ per day with a light intensity of $300 \mu \mathrm{E} \cdot \mathrm{m}^{-2} \cdot \mathrm{s}^{-1}$ at the level of the plants. Plants were watered daily. After 30 days of growth, the plants were harvested. The seedlings were washed with distilled water and partitioned into the following fractions: roots, stems, seed leaves (cotyledons), and true leaves. They were immediately stored at $-80^{\circ} \mathrm{C}$ prior to extraction and HPLC analysis. 


\section{Extraction}

Methods for genistein and daidzein extraction were as follows: Tissues were ground in 4:1 $\mathrm{MeCN} / \mathrm{H}_{2} \mathrm{O}$ (MeCN, acetonitrile), and the mixture was filtered. Distilled water was then added to reduce the concentration of $\mathrm{MeCN}$ to $25 \%$. Organic materials were concentrated on a disposable C18 column, and were then eluted from the column with $100 \% \mathrm{MeCN}$. This final solution was evaporated to dryness and dissolved in a small volume of $\mathrm{MeCN}$. These methods for extraction and partial purification of genistein and daidzein are the same as cited by $\mathrm{O}^{\prime}$ Neill and Saunders (1994) for extraction of the phytoalexin, medicarpin, from alfalfa (Medicago sativa).

\section{Assay}

Fifteen microliters of each sample were assayed by reverse phase (ODS) HPLC $(4.6 \cdot 250$ $\mathrm{mm}$ column size) at $280 \mathrm{~nm}$ and 3000 psi using a linear gradient from $\mathrm{MeCN}: \mathrm{H}_{2} \mathrm{O}: \mathrm{TFA}$ (20: 79.9:0.1) to $\mathrm{MeCN}: \mathrm{H}_{2} \mathrm{O}:$ TFA (86:13.9:0.1) (TFA, trifluoroacetic acid). Genistein and daid-zein concentrations were determined using standard samples of each of these metabolites, with confirmation by mass spectrometry.

\section{RESULTS AND DISCUSSION}

Determination of levels of genistein and daidzein in vegetative parts of legume plants

80 different taxa of legumes were surveyed for their genistein and daidzein contents (Table I). Analyses were conducted on vegetative parts of plants grown from the seeds of these plants or on commercial edible food products made from the plant material. Of these samples, eighteen had significant levels (>50 mg $\cdot \mathrm{kg}^{-1}$ dry wt) of either genistein or daidzein, with four samples containing over $700 \mathrm{mg}$ of these isoflavones per kilogram of dry weight (Table 1). Of special interest are Psoralea corylifolia (Indian breadroot, entry 1a) leaves, which contained over $2 \mathrm{~g}$ of genistein per kilogram of dry weight. It should be mentioned in this connection that the fruit and seed of $P$. corylifolia are commonly used in traditional Chinese medi- cine for skin diseases and as a tonic (Bensky and Gamble, 1990; Chang and But, 1986; Tierra, 1988). Duke (1987) mentions that as an ancient Hindu remedy in India, the seeds of this plant have long been used effectively in treatments for leukoderma and vitiligo. All other legumes had genistein levels $<400 \mathrm{mg} \cdot \mathrm{kg}^{-1}$ of dry weight except for soy miso (entry $3 g$ ), which contained ca $430 \mathrm{mg} \cdot \mathrm{kg}^{-1}$ of dry weight. Daidzein levels, on the other hand, were highest in fava bean stems (Vicia faba; ca 1,025 $\mathrm{mg} \cdot \mathrm{kg}^{-1}$ of dry weight, entry $3 \mathrm{~b}$ ) and kudzu vine roots (Pueraria lobata; ca. $950 \mathrm{mg} \cdot \mathrm{kg}^{-1}$ of dry weight, entry $2 d$ ). Lesser amounts were found in all other samples except soy miso, which contained $327 \mathrm{mg} \cdot \mathrm{kg}^{-1}$ of dry weight. It is notable that both daidzein and genistein levels were relatively high in this commercial fermented soybean product.

Determination of levels of genistein and daidzein in seeds of selected legumes

Levels of daidzein and genistein in seeds for a general selection of legumes are presented in Table 2. Of all the types of legume seeds analyzed, Psoralea seeds were confirmed to have the highest levels of both genistein and daidzein. Seeds having lesser but significant amounts of daidzein included pinto beans and soybeans. Lower but still significant amounts of genistein occurred in yellow split peas, baby lima beans, and black turtle beans. The fact that the level of genistein in soybean seeds is relatively low (as compared with soybean seedlings) is probably due to the fact that most of the genistein found in the seeds occurs as glucosyl or malonyl-glucosyl conjugates (Graham and Graham, 1996; Graham et al., 1990; Matsuura et al., 1989) and, therefore, were not detected in this analysis.

Results from the present study indicate that legumes such as Pueraria lobata (kudzu vine), Lupinus albus (lupine), Vicia faba (fava beans), Glycine max (soybeans), and Psoralea corylifolia (Indian bread root) are excellent sources of the isoflavones, genistein, and daidzein. The levels of these compounds, in general, are greater in seedlings than in the seeds (see Tables I and II). This could be explained by either enhanced isoflavone synthesis and/or release of the 


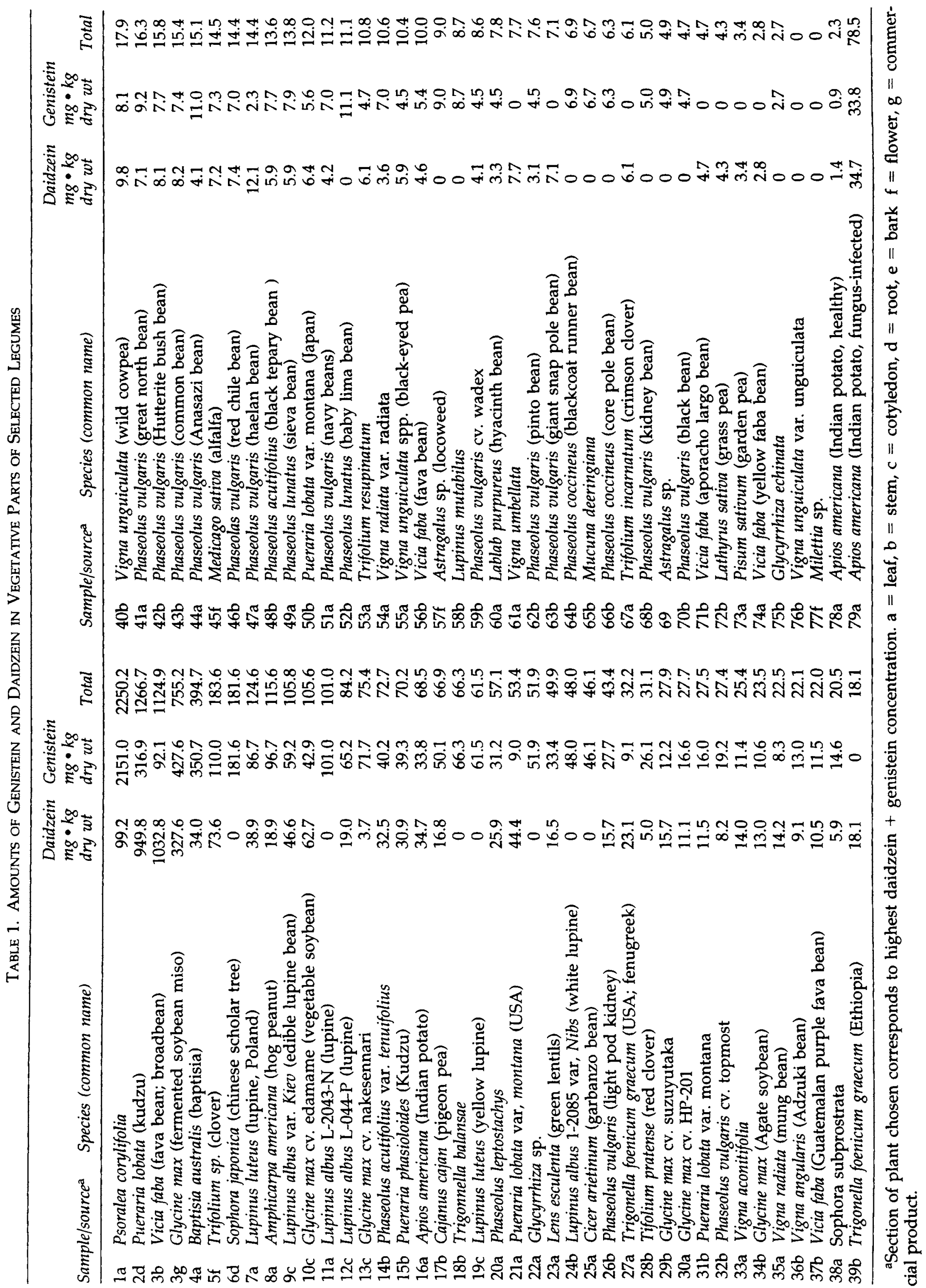


Table 2. Amounts of Daidzein and Geinstein in Seeds of Selected legumes

\begin{tabular}{|c|c|c|c|}
\hline Species (common name) & $\begin{array}{l}\text { Daidzein } \\
m g \bullet k g \\
d r y w t\end{array}$ & $\begin{array}{l}\text { Genistein } \\
m g \bullet k g \\
d r y w t\end{array}$ & Total \\
\hline 1. Psoralea corylifolia & 539.7 & 1528.0 & 2067.7 \\
\hline 2. Glycine max (soybean) & 37.6 & 24.1 & 61.7 \\
\hline 3. Pisum sativum (yellow pea) & 0.4 & 45.8 & 46.2 \\
\hline 4. Phaseolus vulgaris (pinto bean) & 23.2 & 22.3 & 45.5 \\
\hline 5. Phaseolus vulgaris (black turtle bean) & 0.4 & 45.1 & 45.5 \\
\hline 6. Phaseolus vulgaris (baby lima bean) & 0.4 & 40.1 & 40.5 \\
\hline 7. Phaseolus vulgaris (Anasazi bean) & 6.5 & 29.8 & 36.3 \\
\hline 8. Phaseolus lunatus (large lima bean) & 0.3 & 34.4 & 34.7 \\
\hline 9. Phaseolus vulgaris (red kidney bean) & 2.7 & 29.3 & 32.0 \\
\hline 10. Lens esculenta (red lentil) & 5.2 & 25.0 & 30.2 \\
\hline 11. Vigna angularis (Adzuki bean) & 4.6 & 21.2 & 25.8 \\
\hline 12. Phaseolus vulgaris (great northern bean) & 7.2 & 17.7 & 24.9 \\
\hline 13. Vicia faba (fava bean) & 5.0 & 19.9 & 24.9 \\
\hline 14. Vigna unguiculata (black-eyed pea) & 0.3 & 23.3 & 23.6 \\
\hline 15. Vigna radiata (mung bean) & 0.3 & 21.8 & 22.1 \\
\hline 16. Phaseolus vulgaris (red Mexican bean) & 1.4 & 16.3 & 17.7 \\
\hline
\end{tabular}

isoflavones from stored glucosyl or malonyl-glucosyl conjugates through the action of glucosidases during seedling development (Graham et al., 1990, Graham and Graham, 1996). Furthermore, we found that roots of mature kudzu vine (Pueraria lobata) had levels of genistein and daidzein that were almost an order of magnitude higher than in leaves and stems of the seedlings (Table I). Similar findings have been reported by Graham (1991) for soybean seedling root-tips as compared with other seedling organs of soybean.

Our findings on amounts of genistein and daidzein isoflavones in legumes have several important implications for human health and nutrition in addition to the concerns on their use cited in the introduction. They are as follows: (1) Sprouts of the edible species of legumes (e.g., fava beans, Adzuki beans, and soybeans) may be a preferred source of these isoflavones over the seeds for reasons of their higher content of genistein and daidzein, and perhaps, greater availability than with the stored conjugates of these isoflavones that occur in the seeds. Such sprouts, routinely used in Asian diets mainly because of their palatability, high vitamin $C$ content, high levels of soluble protein, and anticancer properties, should be more widely used in our diets for these very reasons. (2) Roots of the edible legume sprouts might be consumed as well as the shoots. A combination of the roots and the cotyledons (seed leaves) of the shoots (the sites of greatest synthesis of genistein and daidzein) provide the highest levels of these isoflavones. (3) Kudzu vine roots, not palatable and edible as such, may provide us with new and rich sources of these isoflavones that could be extracted commercially. Starch from the roots is already available in Oriental stores here in the United States. Kudzu vine is a pernicious and highly competitive vinetype introduced weed in southeastern forests of the United States, and this would certainly be a good use for this otherwise undesirable plant. (4) It would be worthwhile to look at other species of Psoralea, such as P. esculenta, the edible Indian potato of the United States. It is a staple starch crop of native Amerinds. Roots of its relative, $P$. corylifolia, possess the highest levels of both isoflavones of any species we have examined to date (Kaufman et al., 1996).

Finally, the yield data for isoflavones in any legumes must not be looked at in terms of absolute amounts for any given species. The levels of those isoflavones may vary according to environmental conditions, pathogen attack, or chemical races within the germplasm (genotype) of a given legume species. 


\section{ACKNOWLEGMENTS}

The authors wish to thank Mr. Terry Dornbush for his financial support of this research project, Dr. Mark Plummer, Warner-Lambert/ Parke-Davis Pharmaceutical Research Laboratories in Ann Arbor, Michigan, for HPLC assistance and guidance, Dr. Nicolle O'Neill, Plant Pathologist, USDA/ARS/BARC-West, Beltsville, Maryland, for her help with the protocol used for extraction and purification, Judith L. duCellier, of the USDA/ARS/NGRL/ PEO, BARC-West, Beltsville, Maryland, for her kind editorial help, and the following students who helped with the analytical work: Allison Combs, Jennifer Melia, Mary Gratiot, Rachael Williams, Daniel Reichenbach, Aaron Thompson. We express our appreciation to the following individuals who provided Dr. James Duke with seeds for this study: Dr. George White of the USDA/ARS/NGRL in Beltsville, Maryland; Dr. Alan M. Kapuler of Peace Seeds, Corvallis, Oregon; and Dr. Gene Aksland, Resource Seeds, Inc., Visalia, California.

\section{REFERENCES}

Bensky D, Gamble, A. Chinese Herbal Medicine Materia Medica; Eastland Press, Seattle, WA, 1990.

Boik J. Dietary non-nutrient factors and their effects on cancer. In Cancer and Natural Medicine: A Textbook of Basic Science and Clinical Research; Oregon Medical Press, Princeton, MN, 1996.

Chang H, But P. Pharmacology and Applications of Chinese Materia Medica Vol. 1; World Scientific Publishing Co., Teaneck, NJ, 1986.

Dixon R, Dey P, Lamb C. Phytoalexins: Enzymology and molecular biology. Adv. Enzymol. Relat. Areas Mol. Biol. 1983;55,1-136.

Duke J. Psoralea corylifolia L. (Fabaceae). Econ. Bot. 1987;41:524-526.

Duke J. Commentary-Novel psychotherapeutic drugs: a role for ethnobotany. Psychopharmacol. Bull. 1995;31: 177-182.

Fotsis T, Pepper M, Aldercreutz, Hase T, Montesano R, Schweiger L. Genistein, a dietary ingested isoflavonoid, inhibits cell proliferation and in vitro angiogenesis. $L$. Nutrition 1995;125:790s.

Graham T. Flavonoid and isoflavonoid distribution in developing soybean seedling tissues and in seed and root exudates. Pl. Physiol. 1991;95:594-603.

Graham T. Cellular biochemistry of phenylpropanoid re- sponses of soybean to infection by Phytophthora sojae. In Handbook of Phytoalexin Metabolism and Action. Daniel M, Purkayastha R (eds.). Marcel Dekker, New York, 1995.

Graham T, Graham M. Signaling in soybean phenylpropanoid responses. Pl. Physiol. 1996;110:1123-1133.

Graham T, Kim J, Graham M. Role of constitutive isoflavone conjugates in the accumulation of glyceollin in soybean infected with Phytophthora megasperma. Molecular Plant Microbe Interactions 1990;3:157-166.

Kaufman P, Bernal J, Stutland B, Gratiot M, Williams R, Malone W. Synthesis of genistein and daidzein in lightgrown and dark-grown soybeans and Indian breadroot. Pl. Physiol. 1996;111:145.

Kennedy A. The evidence for soybean products as cancer preventive agents. I. Nutrition 1995;125:733s.

Lindsay $W$, Lamb C, Dixon R. Microbiobial recognition and activation of plant defense systems. Trends Microbiol. 1993;1:181-187.

Matsukawa Y, Marui N, Sakai T, Satomi Y, Yoshida M, Matsumoto K, Nishino H, Aoike A. Genistein arrests cell cycle progression at $\mathrm{G}_{2}-\mathrm{M}$. Cancer Res. 1993;53: 1328-1331.

Matsuura M, Obata A, Fukushima D. Objectionable flavor of soy milk developed during the soaking of soybeans and its control. I. Food Science 1989;54:602-605.

O'Neill N, Saunders J. Compatible and incompatible responses in alfalfa cotyledons to races 1 and 2 of Colletotrichum trifolii. J. Phytopathol. 1994;3:283-287.

Oomen A, Dixon R, Paiva N. The elicitor-inductible alfalfa isoflavone reductase promoter confers different patterns of developmental expression in homologous and heterologous transgenic plants. Plant Cell 1994;6: 1789-1803.

Peterson G. Evaluation of the biochemical targets of genistein in tumor cells. I. Nutrition 1995;125:784s.

Stafford H. Isoflavonoid Pathways. In Flavonoid Metabolism. CRC Press, Boca Raton, FL, 1990.

Tierra M. Planetary Herbology. Lotus Press, Twin Lakes, WI, 1988.

Uckun F, Evan W, Forsyth C, Waddick K, Ahlgres L, Chelstrom L, Burkardt A, Bolen J, Myers D. Biotherapy of B-cell precusor leukemia by targeting genistein to CD19-associated tyrosine kinases. Science 1995;267: 886-891.

Zhang F, Smith D. Preincubation of Brachyrhizobium japonicum with genistein accelerates nodule development of soybean at suboptimal root zone temperatures. Plant Physiol. 1995;108:961-968.

Adress reprint requests to:

Peter B. Kaufman

Department of Biology

University of Michigan

4103B Natural Science Building 830 North University Street Ann Arbor, MI 48109-1048 


\section{This article has been cited by:}

1. Cheol-Ho Pan, Eun Sun Kim, Sang Hoon Jung, Chu Won Nho, Jae Kwon Lee. 2008. Tectorigenin inhibits IFN- $/$ /LPS-induced inflammatory responses in murine macrophage RAW 264.7 cells. Archives of Pharmacal Research 31:11, 1447-1456. [CrossRef]

2. Eric Yarnell, Kathy Abascal. 2008. Holistic Approaches to Prostate CancerHolistic Approaches to Prostate Cancer. Alternative and Complementary Therapies 14:4, 164-180. [Abstract] [PDF] [PDF Plus]

3. Wichai CHERDSHEWASART, Suttijit SRIWATCHARAKUL. 2007. Major Isoflavonoid Contents of the 1-Year-Cultivated Phytoestrogen-Rich Herb, Pueraria mirifica. Bioscience, Biotechnology, and Biochemistry 71:10, 2527-2533. [CrossRef]

4. Ara Kirakosyan, Peter B. Kaufman, Soo Chul Chang, Sara Warber, Steven Bolling, Hrachik Vardapetyan. 2006. Regulation of isoflavone production in hydroponically grown Pueraria montana (kudzu) by cork pieces, XAD-4, and methyl jasmonate. Plant Cell Reports 25:12, 1387-1391. [CrossRef]

5. Teruhiko Tamaya. 2006. Phytoestrogens and reproductive biology. Reproductive Medicine and Biology 4:4, 225-229. [CrossRef]

6. T. MEBRAHTU, A. MOHAMED, C.Y. WANG, T. ANDEBRHAN. 2004. Analysis of Isoflavone Contents in Vegetable Soybeans. Plant Foods for Human Nutrition 59:2, 55-61. [CrossRef]

7. Ashish Lal, Sara Warber, Ara Kirakosyan, Peter B. Kaufman , James A. Duke . 2003. Upregulation of Isoflavonoids and Soluble Proteins in Edible Legumes by Light and Fungal Elicitor TreatmentsUpregulation of Isoflavonoids and Soluble Proteins in Edible Legumes by Light and Fungal Elicitor Treatments. The Journal of Alternative and Complementary Medicine 9:3, 371-378. [Abstract] [PDF] [PDF Plus]

8. Elhabib Benlhabib , John I. Baker, Daniel E. Keyler, Ashok K. Singh . 2002. Composition, Red Blood Cell Uptake, and Serum Protein Binding of Phytoestrogens Extracted from Commercial Kudzu-Root and Soy PreparationsComposition, Red Blood Cell Uptake, and Serum Protein Binding of Phytoestrogens Extracted from Commercial Kudzu-Root and Soy Preparations. Journal of Medicinal Food 5:3, 109-123. [Abstract] [PDF] [PDF Plus]

9. K.-D. Hinsch, V. Aires, W. Hagele, E. Hinsch*. 2000. In vitro tests for essential sperm functions using the phyto-oestrogen genistein as a test substance*. Andrologia 32:4-5, 225-231. [CrossRef]

10. John JB Anderson, Mary S Anthony, J Mark Cline, Scott A Washburn, Sanford C Garner. 1999. Health potential of soy isoflavones for menopausal women. Public Health Nutrition 2:04. . [CrossRef] 